\title{
Prevention of ICU delirium and delirium-related outcome with haloperidol: a study protocol for a multicenter randomized controlled trial
}

Mark van den Boogaard ${ }^{*}$, Arjen J Slooter ${ }^{2}$, Roger JM Brüggemann ${ }^{3}$, Lisette Schoonhoven ${ }^{4}$, Michael A Kuiper ${ }^{5}$, Peter HJ van der Voort ${ }^{6}$, Marga E Hoogendoorn ${ }^{7}$, Albert Beishuizen ${ }^{8}$, Jeroen A Schouten ${ }^{9}$, Peter E Spronk ${ }^{10}$, Saskia Houterman ${ }^{11}$, Johannes $G$ van der Hoeven ${ }^{12}$ and Peter Pickkers ${ }^{1}$

\begin{abstract}
Background: Delirium is a frequent disorder in intensive care unit (ICU) patients with serious consequences. Therefore, preventive treatment for delirium may be beneficial. Worldwide, haloperidol is the first choice for pharmacological treatment of delirious patients. In daily clinical practice, a lower dose is sometimes used as prophylaxis. Some studies have shown the beneficial effects of prophylactic haloperidol on delirium incidence as well as on mortality, but evidence for effectiveness in ICU patients is limited. The primary objective of our study is to determine the effect of haloperidol prophylaxis on 28-day survival. Secondary objectives include the incidence of delirium and delirium-related outcome and the side effects of haloperidol prophylaxis.

Methods: This will be a multicenter three-armed randomized, double-blind, placebo-controlled, prophylactic intervention study in critically ill patients. We will include consecutive non-neurological ICU patients, aged $\geq 18$ years with an expected ICU length of stay $>1$ day. To be able to demonstrate a 15\% increase in 28-day survival time with a power of $80 \%$ and alpha of 0.05 in both intervention groups, a total of 2,145 patients will be randomized; 715 in each group. The anticipated mortality rate in the placebo group is $12 \%$. The intervention groups will receive prophylactic treatment with intravenous haloperidol $1 \mathrm{mg} / \mathrm{q} 8 \mathrm{~h}$ or $2 \mathrm{mg} / \mathrm{q} 8 \mathrm{~h}$, and patients in the control group will receive placebo (sodium chloride $0.9 \%$ ), both for a maximum period of 28 -days. In patients who develop delirium, study medication will be stopped and patients will subsequently receive open label treatment with a higher (therapeutic) dose of haloperidol. We will use descriptive summary statistics as well as Cox proportional hazard regression analyses, adjusted for covariates.
\end{abstract}

Discussion: This will be the first large-scale multicenter randomized controlled prevention study with haloperidol in ICU patients with a high risk of delirium, adequately powered to demonstrate an effect on 28-day survival.

Trial registration: Clinicaltrials.gov: NCT01785290.

EudraCT number: 2012-004012-66.

Keywords: Critically ill, Delirium, Haloperidol, Intensive care, Mortality, Prevention, Prophylaxis, Randomized trial

\footnotetext{
* Correspondence: Mark.vandenBoogaard@radboudumc.nl

'Department of Intensive Care Medicine, Radboud University Nijmegen

Medical Centre, P.O. box 9101, internal post 710, 6500HB Nijmegen,

Netherlands

Full list of author information is available at the end of the article
} 


\section{Background}

Delirium is a neuropsychiatric disorder characterized by an acute onset of confusion, inattention, and a change in level of consciousness that tends to fluctuate during the day $[1,2]$. The incidence of delirium in intensive care unit (ICU) patients is high [3-6], approximately $30-50 \%$. Further, its occurrence is associated with detrimental outcome, including prolonged duration of mechanical ventilation, increased ICU and hospital length of stay (LOS) [4-6], unplanned removal of tubes and catheters [6], increased mortality [6-8], and long-term cognitive disturbances $[9,10]$. Therefore, a strategy that can prevent delirium in high-risk patients may also decrease short-term (i.e., 28-day) mortality.

The first step in the management of delirium is to treat the underlying disease. If delirium does not subside, haloperidol is the most frequently used pharmacologic treatment of delirium. However, this drug may also be used to prevent delirium. In non-ICU patients, beneficial effects have been reported of prophylactic haloperidol in older and surgical patients [11,12]. For critically ill patients, data concerning prevention with anti-psychotic drugs are scarce and inconsistent [13-15]. In one retrospective cohort study, ICU patients who received haloperidol were found to have a lower mortality rate compared to ICU patients that did not receive haloperidol [16]. Only one prospective, randomized trial in critically ill patients is available, showing that haloperidol prophylaxis in non-cardiac surgical ICU patients had beneficial effects on delirium incidence and the number of delirium freedays [17]. However, only a very low dose, for $12 \mathrm{~h}$ infusion of haloperidol was administered and many of the patients were in the ICU for less than $24 \mathrm{~h}$ [17]. Thus, there are no large, definitive trials that have studied the effect of haloperidol prophylaxis in ICU patients.

Recently, a model was developed and validated to predict delirium in ICU patients [18]. With this model, the effectiveness of preventive strategies can be compared in different groups that differ in a priori risk of delirium. This delirium prediction model was used to identify highrisk ICU patients (i.e., a priori risk of delirium $>50 \%$ ). Compared to a historical control group, prophylactic low-dose haloperidol was associated with better delirium related outcomes. In this high-risk group ( $>50 \%)$ of critically ill patients, incidence of delirium was significantly lower in the preventive treatment group $(65 \%)$, compared to the control group (75\%). Furthermore, haloperidol prophylaxis was associated with a hazard rate of 0.8 for 28 -day mortality [19]. However, because of the pre-/post-implementation design of this trial, other factors that may have changed between the study periods may have influenced these findings. Nevertheless, the results suggest that prevention of delirium might be beneficial in critically ill patients. Since no relevant side effects associated with the administration of a low dosage of haloperidol were reported in the prophylactic studies $[11,12,17,19]$, it is conceivable that a higher dose of haloperidol may exert more pronounced beneficial effects. Furthermore, the optimal dosage of haloperidol in critically ill patients, as well as the occupancy levels of dopamine- 2 receptors and sigma- 1 receptors when administering haloperidol, remain unknown. Therefore, in the present study proposal the effects of two dosages of haloperidol versus placebo will be determined.

Given the fact that the development of delirium can be predicted only $24 \mathrm{~h}$ after ICU admission, and the clear relation between time to treatment with haloperidol and the duration of delirium [19], initiation of prophylaxis as early as possible is warranted. Based on our historical data, the median predicted risk of delirium is approximately $35 \%$ in patients with an expected stay on the ICU of over one day; this is considered a high risk for delirium development. A clinical estimation of an ICU LOS $>1$ day is possible within the first few hours after ICU admission. Previous studies that included patients using similar criterion of an expected ICU LOS were found feasible $[20,21]$. Therefore, the clinical estimation by the attending ICU-physician of an ICU LOS $>1$ day will be used as an inclusion criterion for this study, in which the prediction to develop delirium (using the PRE-DELIRIC model [18]) will be used to facilitate post-hoc analyses to investigate which patients benefit most from prophylactic therapy. By using the PRE-DELIRIC score as an a priori determined post-hoc analysis, we will learn if the putative beneficial effect of haloperidol is related to the risk to develop delirium, or comparable in all patients, independent of the baseline risk to develop delirium. In addition, it will facilitate the determination of a cut-off level for the PRE-DELIRIC score.

Potential side effects of haloperidol include extra pyramidal symptoms, drowsiness, agitation, and ventricular arrhythmias. The latter are extremely rare (only case-reports are published [22-25]) and dose dependent. With the haloperidol dosage that will be used in the present study (3x1 mg or $3 \times 2 \mathrm{mg}$ intravenously daily), no relevant side effects are expected, regardless of underlying condition, organ dysfunction, and concomitant medication. Nevertheless, and given the preventive nature of this study, extra attention is being paid to the recognition of possible side effects of haloperidol that could mitigate its potential beneficial effects. Importantly, in three recent prophylactic haloperidol studies $[11,17,19]$ no relevant side effects, and in particular no ventricular arrhythmias, were reported using similar low dosages of haloperidol as described in the present protocol. Regarding the choice of haloperidol dosage, this was based on the previous study in which no relevant side effects were found when using a prophylactic dose of $3 \times 1 \mathrm{mg}$ in delirium high-risk ICU patients, and resulted in a significant decrease of delirium incidence [19]. However, in this 
high-risk group (mean delirium risk of $75 \%$ ) the incidence was still $65 \%$, suggesting that a higher dosage of haloperidol might decrease the incidence of delirium to a greater extent. For this reason, and taking into account the non-relevant side effects, we choose to add a third arm using a higher dose of $3 \times 2 \mathrm{mg}$ haloperidol.

The aim of this study is firstly to determine the effect of two different low dosages of prophylactic haloperidol on 28-day mortality as well as the incidence of delirium and other delirium related outcome measures and quality of life, compared with placebo, in ICU patients with an expected ICU stay of $>1$ day. Secondly, to relate the potential beneficial effects of haloperidol to the a priori risk of developing delirium, using the PRE-DELIRIC model [18]. Lastly, to evaluate possible side effects of prophylactic haloperidol.

\section{Methods}

This study protocol is in accordance with the CONSORT guidelines concerning randomized controlled trials [26].

\section{Design and setting}

A prospective, multicenter, three-armed, permuted blockrandomized, double-blind, placebo-controlled, prophylactic intervention study will be conducted in critically ill patients with a high risk of delirium development. All participating sites are members of the Dutch Intensive Care Unit Delirium Consortium facilitating the collaboration related to delirium research in the ICU. In all centers, patients are screened for delirium using the validated Dutch translation of the Confusion Assessment Method-Intensive Care Unit (CAM-ICU) [27-29] by well-trained ICU nurses, at least two times a day and more often if indicated (during periods of fluctuating symptoms or levels of sedation). Before initiation of the study, ICU nurses will receive additional information concerning the CAM-ICU on top of their in-house CAM-ICU training. Furthermore, during the study, inter-rater reliability measurements of the CAM-ICU and the Richmond Agitation Sedation Score (RASS), as part of the CAM-ICU, will be performed in order to check the quality of the assessments, and if necessary, additional training will be provided.

The study will start after training of all centers including an initiation visit.

\section{Study population \\ Inclusion criteria}

All consecutive critically ill patients admitted to the ICU aged $\geq 18$ years at the time of ICU admission and with an expected length of ICU stay of over one day will be included as informed consent is obtained.

Data from patients that are included in the study, but who do not receive any study drug and are discharged from the ICU within $24 \mathrm{~h}$ will be discarded from further analysis. Patients who received at least one dose will remain in the study and patients in whom study medication had to be halved or stopped, e.g., because of prolonged QTc time or other side effects, will remain allocated to their study group and analyzed on an intention-to-treat basis.

\section{Exclusion criteria}

The following will be considered exclusion criteria: no informed consent obtained; history of epilepsy, Parkinson's disease, hypokinetic rigid syndrome, dementia or alcohol withdrawal syndrome; patients admitted to the ICU for any other neurological disease (including post-cardiopulmonary resuscitation patients, and patients admitted with coma due to overdose); patients treated with antipsychotic therapy over the last 30 days prior to ICU admission; prolonged QTc-time (>500 msec) or history of clinically relevant ventricular arrhythmia in last 12 months; pregnancy/breast feeding; documented delirium prior to ICU admission; reasons that impair delirium assessment with the CAM-ICU (serious auditory or visual disorders, unable to understand Dutch or English; severely mentally disabled; serious receptive aphasia); ICU-stay less than one day; moribund and not expected to survive two days; known allergy to haloperidol.

\section{Objectives}

Definitions of variables in objectives are reported in Table 1.

\section{Primary objective}

To determine the effect of prophylactic haloperidol use on 28-days survival.

\section{Secondary objectives}

There are seven secondary objectives:

1. To determine the effect of prophylactic haloperidol use on 90-day survival; survival analysis stratifying for delirium incidence will be performed.

2. To determine the effect of prophylactic haloperidol use on the incidence of delirium.

3. To determine the effect of prophylactic haloperidol use on the number of delirium- and coma-free days in a period of 28 days.

4. To determine the effect of prophylactic haloperidol use on delirium related outcomes: time to successful extubation, incidence of re-intubation, incidence of ICU readmission, and incidence of unplanned removal of tubes and catheters.

5. To evaluate the incidence and severity of side effects of haloperidol prophylaxis.

6. To determine the effect of preventive haloperidol use on quality of life 1 and 6 months following ICU admission compared with a baseline measurement at 
Table 1 Definition of study objectives

\begin{tabular}{|c|c|}
\hline Objective & Definition \\
\hline Survival days in 28 days & $\begin{array}{l}\text { Number of days that patients survive in } 28 \text { days. All patients will be classified as either 'alive at study } \\
\text { day } 28 \text { ' or, if dead, 'dead at study day } 28 \text { ' on an intention-to-treat basis. }\end{array}$ \\
\hline Delirium diagnosis & $\begin{array}{l}\text { Patients are diagnosed as delirious when they have at least one positive CAM-ICU screening during } \\
\text { their complete ICU stay. Patients who were not delirious during their ICU-stay are considered as } \\
\text { non-delirious patients. }\end{array}$ \\
\hline Delirium-and-coma-free days in 28 days & $\begin{array}{l}\text { Number of days that the patient is alive and not delirious and not in coma over } 28 \text { days starting from } \\
\text { the day of inclusion. A delirium-and-coma-free day is defined as a negative CAM-ICU screening with a } \\
\text { Richmond Agitation Sedation Score (RASS) greater than (more alert than) -3/-4/-5 during a day. In case } \\
\text { a delirious patient is discharged to the ward, a delirium-free day is defined as a delirium observation } \\
\text { scale score [30] of less than } 3 \text { during a complete day. }\end{array}$ \\
\hline Duration of mechanical ventilation & $\begin{array}{l}\text { Time in days that the patient is on the mechanical ventilator. If the patient is ventilated mechanically } \\
\text { several times during one ICU admission, then the ventilator times are added. Both invasive and } \\
\text { non-invasive ventilation will be registered. Ventilator-free days (in } 28 \text { days) will be calculated. }\end{array}$ \\
\hline Incidence of re-intubation & $\begin{array}{l}\text { Patients who need to be intubated within } 28 \text { days from randomization, following a previous extubation, } \\
\text { irrespective of the reason for re-intubation, are counted as incident case for re-intubation. }\end{array}$ \\
\hline Incidence of ICU readmission & $\begin{array}{l}\text { Patients who need to be readmitted to the ICU during within } 28 \text { days from randomization, irrespective } \\
\text { of the reason for readmission, are counted as incident cases for ICU readmission. }\end{array}$ \\
\hline Side effects & $\begin{array}{l}\text { Drowsiness, agitation, QTc-time prolongation (using 12-leads ECG or monitor strip with Bazett's formula) } \\
\text { and development of extra pyramidal symptoms such as tandem gait, dystonia, tremor, myoclonus, tics, } \\
\text { rigidity, akathisia [31], determined daily by physical examination by the intensivist. }\end{array}$ \\
\hline \multirow[t]{7}{*}{ Serious adverse event } & $\begin{array}{l}\text { Any untoward medical occurrence or effect at any dose that results in one of the following outcomes } \\
\text { and is not classified as a clinical outcome of delirium or the underlying disease using the description above: }\end{array}$ \\
\hline & $\begin{array}{l}\text { - death that is not related to the underlying disease or sequel of the underlying disease, or death } \\
\text { that is considered by the investigator to be related to study drug }\end{array}$ \\
\hline & - prolonged inpatient hospitalization or re-hospitalization \\
\hline & - a life-threatening experience (that is, immediate risk of dying) \\
\hline & - persistent or significant disability/incapacity \\
\hline & - congenital anomaly/birth defect \\
\hline & - considered significant by the investigator for any other reason \\
\hline Sudden unexpected serious adverse reactions & $\begin{array}{l}\text { Unexpected adverse reactions are adverse reactions, of which the nature, or severity, is not consistent } \\
\text { with the applicable product information. Adverse reactions are all untoward and unintended responses } \\
\text { to an investigational product related to any dose administered. }\end{array}$ \\
\hline
\end{tabular}

ICU admission using the Short Form-12 (SF-12) questionnaire.

7. A priori defined post-hoc analyses:

a. To determine the preventive effectiveness of haloperidol in different patient groups based on the $a$ priori risk to develop delirium: patients with a predicted risk up to $50 \%, 50-70 \%, 70-90 \%$, above $90 \%$ will be evaluated.

b. To determine the preventive effectiveness of haloperidol in different patient groups: medical/ surgical/trauma patients, per acute physiology and chronic health evaluation-II (APACHE-II) score $(<20,20-25,>25)$

c. Effectiveness of prophylaxis when delirium is diagnosed based on 1,2, or more days with positive CAM-ICU scoring.

\section{Randomization}

Block randomization will be applied by the pharmacist. The randomization numbers are coupled with the Clinical
Report Form (CRF) number and the number of study medication box. Boxes are numbered and consist of 12 ampoules of study drug. If necessary, when a patient is admitted to the ICU for more than 4 days and is not delirious, a new box will be assigned to this patient consisting of the same study regime as the previous box. All study medication will be manufactured by the Department of Clinical Pharmacy of the Radboud University Nijmegen Medical Centre, which holds a Good Manufacturing Practice certificate. Ampoules of study medication consist of $1 \mathrm{mg} / \mathrm{mL}$ or $2 \mathrm{mg} / \mathrm{mL}$ haloperidol or $1 \mathrm{~mL}$ sodium chloride $0.9 \%$ solution, all with a total volume of $1 \mathrm{~mL}$. The randomization code is kept by the pharmacist and will be broken only if necessary for safety reasons. Only the pharmacist of the Radboud University Nijmegen Medical Centre is unblinded for this study.

\section{Intervention and control group}

This study involves a comparison of prophylactic haloperidol in a dosage of $1 \mathrm{mg}$ (intervention group 1) or $2 \mathrm{mg}$ 
(intervention group 2) administered as a bolus intravenously three times a day compared with placebo of $0.9 \%$ sodium chloride (control group) administered intravenously three times a day in a double-blind fashion. All ampoules and drug boxes have an identical appearance.

To decrease the likelihood of encountering side effects in specific cohorts, the dose of the study drug will be halved in patients aged $\geq 80$ years, weighing $\leq 50 \mathrm{~kg}$, suffering from liver failure (indicated by serum bilirubin level $>50 \mu \mathrm{mol} / \mathrm{L}$ ) present at time of inclusion or during the study. Patients with an adjusted dose remain allocated to their original group (intention-to-treat).

Patients with an adjusted dose remain allocated to their original group (intention to treat).

\section{End of study medication}

Prophylactic treatment with haloperidol will be continued until day 28, or discharge from the ICU (whatever comes first), or until delirium occurs. In the latter case, patients will be subsequently treated according to the delirium treatment protocol (with higher dosage of open label haloperidol).

In case delirium occurs, the patient's study medication (prophylaxis treatment) will be stopped and the patient will be treated with open label haloperidol according to the delirium treatment protocol described below. Analysis will be on intention-to-treat basis. Study medication will not be restarted once delirium subsides, therapeutic haloperidol is stopped, or when a patient is re-admitted to the ICU within 28 days.

\section{Delirium treatment}

Patients with delirium (defined as a positive CAM-ICU test) will be treated with $2 \mathrm{mg}$ haloperidol intravenously three times daily. Patients suffering from hypoactive delirium (only RASS scores between 0 and -3 ) and patients aged $\geq 80$ years, weighing $\leq 50 \mathrm{~kg}$, or with liver failure, will be treated with a lower dosage of 3x1 mg intravenously. Dosage can be increased up to a maximum of $3 \times 5 \mathrm{mg}$ in case of serious agitation or anxiety due to delirium. Additionally, midazolam, clonidine, propofol, or dexmedetomidine can be used as an escape therapy in case of serious agitation with insufficient efficacy of haloperidol according to usual patient care.

In patients treated for more than three days, the dosage will be halved when delirium subsides. When delirium does not reoccur the following day (CAM-ICU remains negative), the dosage will be halved again and then stopped the third day when the patient remains non-delirious. In case delirium occurs again during the reducing phase, the original dose will be restarted.

\section{Data collection}

All data will be collected electronically in an electronic CRF (E-CRF). The E-CRF is a secured website where the participating hospitals must login using a unique password. Participating hospitals will only have access to their own data.

Demographic variables will be collected from all patients, including age, gender, PRE-DELIRIC score, APACHE-II score, and diagnosis group. Furthermore, outcome related variables will be collected (Table 2) as well as variables that may influence the delirium outcome, i.e., dexmedetomidine [32] and early mobilization [33]. Concerning the study medication, we will collect data on the amount of study drug administered as well as open-label haloperidol and other anti-delirium drugs administered in case delirium occurs.

\section{Safety monitoring and safety issues}

A Data Safety Monitor Board (DSMB) is established for this study to perform ongoing safety surveillance and to perform interim analyses on the safety data. This is an independent committee composed of two physicians/ researchers (a psychiatrist and an anesthetist) and a statistician. The DSMB will perform all interim analyses. To assess side effects of haloperidol and to determine superiority of the intervention or placebo the DSMB will be unblinded for this study, while all researchers remain blinded. Furthermore, the study will be monitored by an independent researcher who will monitor the trial master file, and perform random checks of informed consent forms, drug accountability lists, and source data of primary and secondary outcome measures.

Concerning safety issues, during a patient's treatment with the study medication, known side effects of haloperidol [34] are pro-actively collected with a special focus on prolonged QTc-time, drowsiness, extrapyramidal symptoms, and agitation and sedation effects. All side effects will be collected during patients' treatment with the study medication until $24 \mathrm{~h}$ after stopping the study medication. In case of the occurrence of side effects, physicians can reduce the dosage or stop the study medication, depending on the severity of the occurred side effect and at the discretion of the attending physician. Only for prolonged QTc-time, strict stopping rules are applied, as described below. To detect side effects of haloperidol, the protocol dictates that patients are physically examined every day for known signs of extrapyramidal symptoms (signs of Parkinsonism and/or akathisia and/or dystonia). Furthermore, daily QTctime is calculated using a 12-lead ECG or a monitor lead ECG. A QTc-time of over $500 \mathrm{msec}$ combined with an increase of over 10\% of baseline QTc-time is defined as prolonged QTc-time. In case of QTc-time prolongation, the study drug is temporarily stopped until QTctime is normalized. After normalization of QTc-time $(<500 \mathrm{msec})$ the study drug will be restarted. If QTc-time becomes prolonged again, the study drug will be stopped 
Table 2 Primary, secondary endpoints and posthoc analyses

\begin{tabular}{|c|c|c|}
\hline Primary endpoint & Secondary endpoints & Post-hoc analyses \\
\hline \multirow[t]{7}{*}{ 28-day mortality } & $\begin{array}{l}\text { 90-day mortality } \\
\text { Delirium incidence }\end{array}$ & $\begin{array}{l}\text { Effectiveness in groups of predicted risk up to } 50 \% \text {, } \\
50-70 \%, 70-90 \% \text {, above } 90 \% \text { will be evaluated }\end{array}$ \\
\hline & Number of delirium and coma free-days in 28 days & $\begin{array}{l}\text { Effectiveness in diagnosis groups: medical, surgical } \\
\text { and trauma patients }\end{array}$ \\
\hline & Duration of mechanical ventilation & Effectiveness per APACHE-II score: $<20,20-25,>25$ \\
\hline & Incidence of unintended tube or catheter removal & $\begin{array}{l}\text { Effectiveness in groups with 1,2, or more positive } \\
\text { CAM-ICU scores }\end{array}$ \\
\hline & Incidence of ICU re-admission & \\
\hline & $\begin{array}{l}\text { Quality of life measured at time of ICU admission, } \\
\text { after } 1 \text { and } 6 \text { months using SF-12 }\end{array}$ & \\
\hline & $\begin{array}{l}\text { Incidence and severity of side effects of prophylactic } \\
\text { haloperidol (all patients) }\end{array}$ & \\
\hline
\end{tabular}

definitively. The patient will remain allocated to the original study group.

To determine long-term side effects, such as rigidity, and quality of life, a recommended and validated quality of life questionnaire, SF-12 [35], is taken at the time of admission and is sent to the patients 1 and 6 months after ICU admission.

The following adverse events will be collected: serious adverse events; non-serious adverse events that are considered by the investigator to be possibly related to the study drug (e.g., prolonged QTc-time, drowsiness, extrapyramidal symptoms, agitation and sedation effects); adverse events that lead to permanent discontinuation of the study drug administration. A serious adverse event is any untoward medical occurrence or effect at any dose that results in one of the following outcomes and is not classified as a clinical outcome of delirium or the underlying disease using the description: death that is not related to the underlying disease or sequel of the underlying disease, or death that is considered by the investigator to be related to the study drug; prolonged inpatient hospitalization or re-hospitalization; a lifethreatening experience (that is, immediate risk of dying); persistent or significant disability/incapacity; considered significant by the investigator for any other reason.

\section{Sample size calculation and statistics}

Sample size calculation is based on the difference in survival from our previous prophylactic haloperidol study [19]. In this study, the median survival time in the control group was 18 days. If the true hazard ratio of control patients relative to intervention patients is 0.85 , taking into account an accrual time of 90 days with 28 days of follow-up, we will need to study 647 patients per intervention group and 647 control patients to be able to reject the null hypothesis that the experimental and control survival curves are equal with probability (power) 0.80 . The Type I error probability associated with this null hypothesis test is 0.05 . Taking into account a dropout percentage of $10 \%$, we will include 715 patients per group (Figure 1). A fixed sequence procedure will be followed. First, the highest dosage of prophylactic haloperidol will be compared with placebo using alpha 0.05 (two-sided). Only if $\mathrm{H}_{0}$ is rejected, subsequently the lower dosage of prophylactic haloperidol will be compared with placebo. Cox regression analysis will be used to test differences on 28-day survival in the intervention group compared with the placebo group.

A safety, futility, and superiority interim analysis will be performed by the DSMB after 175, 350, 500 (safety and futility) and 1,000 (safety and superiority) patients are included. Differences in serious adverse events between intervention and placebo are used for safety analyses and the primary endpoint 28-day survival is used to determine futility or superiority of intervention or placebo.

After the inclusion of 1,000 patients, superiority will be tested. A proven superiority $(P<0.003$, two-sided $)$ of any dose of haloperidol over placebo or a proven superiority $(P<0.003$, two-sided $)$ of placebo over haloperidol determined during the interim analysis will result in an alpha of 0.049 (two-sided) for the final analysis. This alpha distribution was calculated by an independent statistician according to the method of Lan-DeMets cumulative alpha spending function of O'Brien-Fleming alpha spending [36].

Data will be analyzed according to the intention-totreat principle. For the descriptive statistics, continuous variables will be given as mean with standard deviation or median and inter quartile ranges, depending on their distribution. Normally distributed variables will be tested using Student's $t$-test for comparison and Mann-Whitney U-tests for non-normally distributed variables. Categorical (and binary) variables will be presented as numbers and percentages and will be analyzed using the $\chi^{2}$ test. Survival analyses with Kaplan-Meier curves will be used as graphical representation. Cox proportional hazard regression analyses will be used to estimate the hazard ratio for survival with the use of haloperidol versus placebo. Furthermore, we will perform adjusted analyses for relevant covariates 


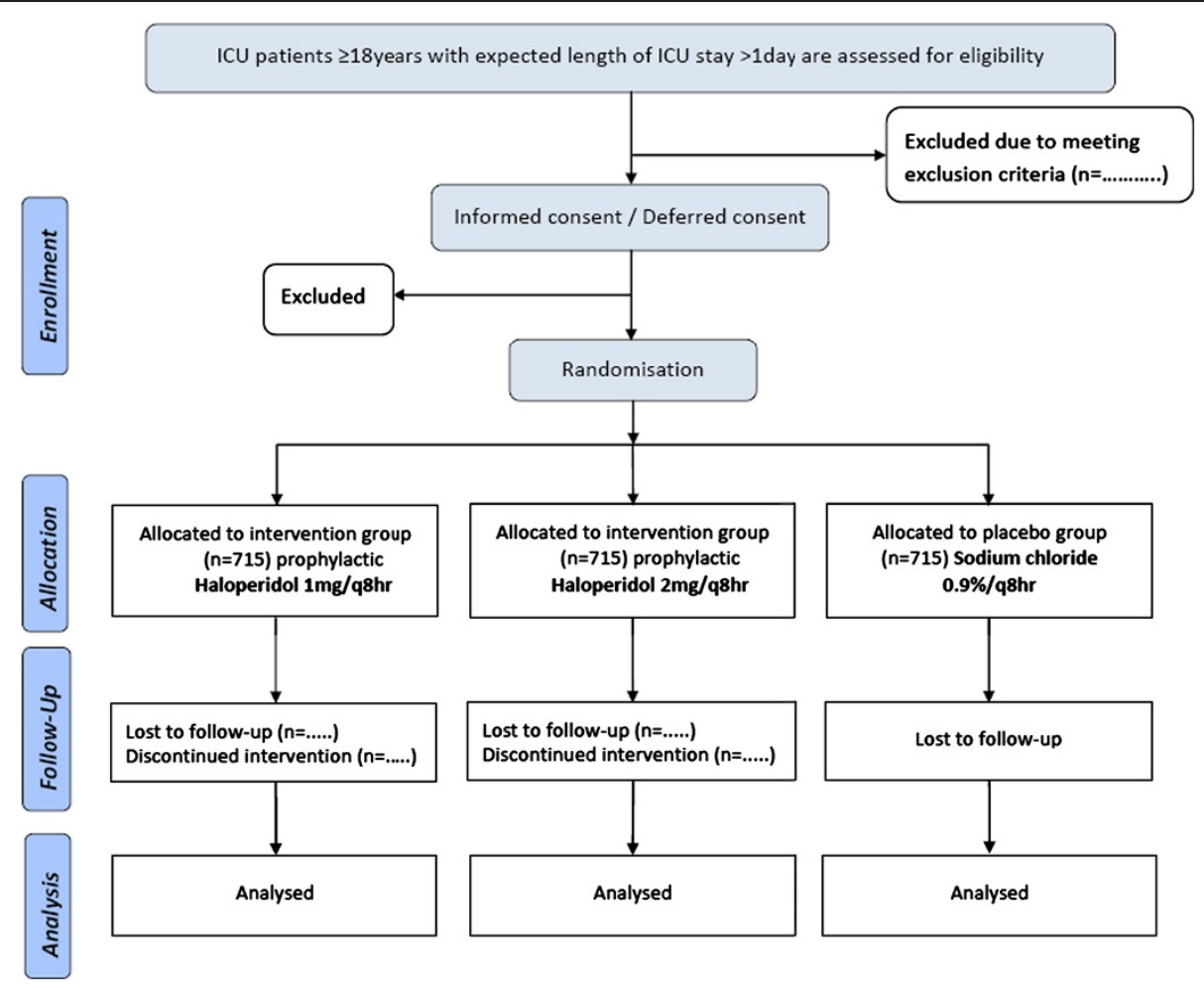

Figure 1 CONSORT flowchart of patient enrollment.

(including delirium, APACHE-II score, age, sex, sepsis, and other differences between the three study groups irrespective of the possible imbalance between the three groups). For this covariate analysis, univariate logistic regression analysis will be performed first in order to test the strength of the relationship. Subsequently, variables significantly associated with the dependent variable will be included in the covariate analyses.

Furthermore, subgroup analysis will be performed by direct comparisons of a priori specified subgroups, i.e., predicted risk group, admission type group, and APACHE-II group, in order to determine effectiveness of prophylactic haloperidol treatment in these subgroups on 28-day survival.

All statistical tests are two-sided and statistical significance is defined as a $P$ value $<0.05$. All data will be analyzed using SPSS version 20.01 (SPSS, Chicago, IL, USA).

\section{Ethics}

The study will be conducted according to the principles of the Declaration of Helsinki (version 2008) and in accordance with the Medical Research Involving Human Subjects Act.

There are indications that early treatment of delirium is more effective than delayed treatment [37], but this needs to be confirmed in other studies. Since it is recognized that the onset of delirium occurs, on average, on day 2 after ICU admission, early preventive treatment is likely to be more effective. In the short-term, low dose haloperidol has no known relevant side effects, therefore randomization and administration of study medication will be started immediately following identification of a high-risk patient. When an informed consent procedure results in a delay of randomization, a deferred consent procedure may be followed. The informed consent procedure will be started as soon as possible, but always within $24 \mathrm{~h}$ following ICU admission. If no deferred informed consent can be obtained within $24 \mathrm{~h}$, the patient will be excluded from the study and study drug administration will be stopped.

The medical ethical committee of Arnhem-Nijmegen (CMO) approved this study including this deferred consent procedure (CMO-number 2012/424). This trial is registered on clinicaltrials.gov: NCT01785290.

\section{Discussion and trial status}

This is the first large-scale multicenter randomizedcontrolled prevention study with haloperidol in ICU patients with an increased risk to develop delirium. The study design and protocol was finalized in 2012 and the protocol passed the medical ethical committee on February 2013. Prior to the start of the study, all centers will be visited to inform all involved researchers and a second meeting will take place as an initiation visit. Furthermore, a meeting with the DSMB and the monitor will be scheduled prior to the conduction of the study. 
Results of our study will be of importance for critically ill patients and permits us to draw conclusions on the effectiveness of haloperidol prophylaxis in reducing 28-day mortality, preventing delirium, and improving deliriumrelated outcome. Furthermore, it will provide information regarding the delirium-risk category in which the PREDELIRIC model prophylaxis is most effective. Positive effects of haloperidol prophylaxis on delirium outcome will result in the alteration of daily practice for critically ill patients and would therefore have major implications. However, if there is no effect of haloperidol prophylaxis, other possibilities of delirium prevention, such as nursing interventions, need to be studied. In addition, the effectiveness of nursing interventions focusing on delirium prevention can be studied in conjunction with haloperidol prophylaxis.

\section{Trial status}

Preparations of the study are nearing completion. We expect that the study will start mid-2013.

\section{Abbreviations}

APACHE-II: Acute physiology and chronic health evaluation-II;

CAM-ICU: Confusion assessment method-intensive care unit; DSMB: Data safety monitoring board; E-CRF: Electronic clinical report form; ICU: Intensive care unit; LOS: Length of stay; RASS: Richmond agitation sedation scale.

\section{Competing interests}

The authors declare that they have no competing interests related to this study.

\section{Authors' contributions}

MvdB, AS, and PP designed the study and wrote the protocol. MvdB is the principal investigator. PP is project leader and AS and $\mathrm{JH}$ are sub-investigators. AS, PP, and LS, will supervise the conduct of the study. $\mathrm{SH}$ supported the study design and protocol with statistical advice. RB supported the study protocol with regard to study drug advises. MvdB, $A S, M K, P v d V, M H, A B$, JS, and PS are responsible for conducting the study in their hospital. JvdH co-supervised and corrected the manuscript. All authors read and approved the final manuscript.

\section{Acknowledgements}

The authors wish to thank all co-investigators, their research nurses, and their intensive care teams at each of the sites open for recruitment for this trial. Furthermore, we wish to thank the data safety monitoring board members, Prof. Dr. G. Scheffer (anesthesiologist), Dr. M. Pop-Purseleanu (psychiatrist), and T. de Haan, MSc (statistician) for willingness to perform interim and safety analyses. This study is not funded.

\section{Author details}

${ }^{1}$ Department of Intensive Care Medicine, Radboud University Nijmegen Medical Centre, P.O. box 9101, internal post 710,6500HB Nijmegen, Netherlands. ${ }^{2}$ Department of Intensive Care Medicine, University Medical Centre Utrecht, PO box 85090, 3508AB Utrecht, Netherlands. ${ }^{3}$ Department of Clinical Pharmacy, Radboud University Nijmegen Medical Centre, PO box 9101, 6500HB Nijmegen, Netherlands. ${ }^{4}$ Scientific Institute for Quality of Healthcare, Radboud University Nijmegen Medical Centre, PO box 9101, $6500 \mathrm{HB}$ Nijmegen, Netherlands. ${ }^{5}$ Department of Intensive Care Medicine, Medical Centre Leeuwarden, Henri Dunantweg 2, 8934AD Leeuwarden, Netherlands. 'Department of Intensive Care Medicine, Onze Lieve Vrouwe Gasthuis, Oosterpark 9, 1091AC Amsterdam, Netherlands. ${ }^{7}$ Research Department of Anesthesiology \& Intensive Care, ISALA clinic, PO box 10400, 8000GK Zwolle, Netherlands. 'Department of Intensive Care Medicine, Medical Spectrum Twente, PO box 50000, 7500KA Enschede, Netherlands. ${ }^{9}$ Department of Intensive Care Medicine, Canisius Wilhelmina Hospital, PO box 9015, 6500GS Nijmegen, Netherlands. ${ }^{10}$ Department of Intensive Care
Medicine, Gelre Hospitals, Location Lukas, Albert Schweitzerlaan 31, 7334DZ Apeldoorn, Netherlands. ${ }^{11}$ Catharina Hospital, Michelangelolaan 2, 5623EJ Eindhoven, Netherlands. ${ }^{12}$ Department of Intensive Care Medicine, Radboud University Nijmegen Medical Centre, PO box 9101, 6500HB Nijmegen, Netherlands.

Received: 2 May 2013 Accepted: 13 November 2013 Published: 21 November 2013

\section{References}

1. Association AP: Diagnostic and statistical manual of mental disorders (DSM-V). Arlington, VA: American Psychiatric Publishing; 2013.

2. Dubois MJ, Bergeron N, Dumont M, Dial S, Skrobik Y: Delirium in an intensive care unit: a study of risk factors. Intensive Care Med 2001, 27:1297-1304.

3. American college of chest physicians/society of critical care medicine consensus conference: definitions for sepsis and organ failure and guidelines for the use of innovative therapies in sepsis. Crit Care Med 1992, 20:864-874.

4. Ely EW, Gautam S, Margolin R, Francis J, May L, Speroff T, Truman B, Dittus R, Bernard $R$, Inouye SK: The impact of delirium in the intensive care unit on hospital length of stay. Intensive Care Med 2001, 27:1892-1900.

5. Ouimet S, Kavanagh BP, Gottfried SB, Skrobik Y: Incidence, risk factors and consequences of ICU delirium. Intensive Care Med 2007, 33:66-73.

6. van den Boogaard M, Schoonhoven L, van der Hoeven JG, van Achterberg T, Pickkers P: Incidence and short-term consequences of delirium in critically ill patients: a prospective observational cohort study. Int J Nurs Stud 2012, 49:775-783.

7. van den Boogaard M, Peters SA, van der Hoeven JG, Dagnelie PC, Leffers P, Pickkers $\mathrm{P}$, Schoonhoven $\mathrm{L}$ : The impact of delirium on the prediction of in-hospital mortality in intensive care patients. Crit Care 2010, 14:R146.

8. Ely EW, Shintani A, Truman B, Speroff T, Gordon SM, Harrell FE Jr, Inouye SK, Bernard GR, Dittus R: Delirium as a predictor of mortality in mechanically ventilated patients in the intensive care unit. J Amer Med Assoc 2004, 292:168-169.

9. van den Boogaard M, Schoonhoven L, Evers AW, van der Hoeven JG, van Achterberg T, Pickkers P: Delirium in critically ill patients: impact on long-term health-related quality of life and cognitive functioning. Crit Care Med 2012, 40:112-118.

10. Girard TD, Jackson JC, Pandharipande PP, Pun BT, Thompson JL, Shintani AK, Gordon SM, Canonico AE, Dittus RS, Bernard GR, Ely EW: Delirium as a predictor of long-term cognitive impairment in survivors of critical illness. Crit Care Med 2010, 38:1513-1520.

11. Kalisvaart KJ, de Jonghe JF, Bogaards MJ, Vreeswijk R, Egberts TC, Burger BJ, Eikelenboom P, van Gool WA: Haloperidol prophylaxis for elderly hipsurgery patients at risk for delirium: a randomized placebo-controlled study. J Am Geriatr Soc 2005, 53:1658-1666.

12. Kaneko T, Cai J, Ishikura T, Kobayashi M, Naka T, Kaibara N: Prophylactic consecutive administration of haloperidol can reduce the occurrence of postoperative delirium in gastrointestinal surgery. Yonago Acta Med 1999, 42:179-184.

13. Prakanrattana $U$, Prapaitrakool S: Efficacy of risperidone for prevention of postoperative delirium in cardiac surgery. Anaesth Intensive Care 2007, 35:714-719.

14. Gamberini M, Bolliger D, Lurati Buse GA, Burkhart CS, Grapow M, Gagneux A, Filipovic M, Seeberger MD, Pargger H, Siegemund M, Carrel T, Seiler WO, Berres M, Strebel SP, Monsch AU, Steiner LA: Rivastigmine for the prevention of postoperative delirium in elderly patients undergoing elective cardiac surgery-a randomized controlled trial. Crit Care Med 2009, 37:1762-1768.

15. Girard TD, Pandharipande PP, Carson SS, Schmidt GA, Wright PE, Canonico AE, Pun BT, Thompson JL, Shintani AK, Meltzer HY, Bernard GR, Dittus RS, Ely EW, MIND Trial Investigators: Feasibility, efficacy, and safety of antipsychotics for intensive care unit delirium: the MIND randomized, placebo-controlled trial. Crit Care Med 2010, 38:428-437.

16. Milbrandt EB, Kersten A, Kong L, Weissfeld LA, Clermont G, Fink MP, Angus DC: Haloperidol use is associated with lower hospital mortality in mechanically ventilated patients. Crit Care Med 2005, 33:226-229.

17. Wang W, Li HL, Wang DX, Zhu X, Li SL, Yao GQ, Chen KS, Gu XE, Zhu SN: Haloperidol prophylaxis decreases delirium incidence in elderly 
patients after noncardiac surgery: a randomized controlled trial. Crit Care Med 2012, 40:1-9.

18. van den Boogaard M, Pickkers P, Slooter AJ, Kuiper MA, Spronk PE, van dV, van der Hoeven JG, Donders R, van AT, Schoonhoven L: Development and validation of PRE-DELIRIC (PREdiction of DELIRium in ICu patients) delirium prediction model for intensive care patients: observational multicentre study. BMJ 2012, 344:e420-e420.

19. van den Boogaard M, Schoonhoven L, Van Achterberg T, Van der Hoeven $J G$, Pickers P: Haloperidol prophylaxis in critically ill patients with a high risk for delirium. Crit Care 2013, 17:R9.

20. de Smet AM, Kluytmans JA, Cooper BS, Mascini EM, Benus RF, van der Werf TS, van der Hoeven JG, Pickkers P, Bogaers-Hofman D, van der Meer NJ, Bernards AT, Kuijper EJ, Joore JC, Leverstein-van Hall MA, Bindels AJ, Jansz AR, Wesselink RM, de Jongh BM, Dennesen PJ, van Asselt GJ, te Velde LF, Frenay IH, Kaasjager K, Bosch FH, van Iterson M, Thijsen SF, Kluge GH, Pauw W, de Vries JW, Kaan JA, et al: Decontamination of the digestive tract and oropharynx in ICU patients. N Engl J Med 2009, 360:20-31.

21. Heyland DK, Dhaliwal R, Jiang X, Day AG: Identifying critically ill patients who benefit the most from nutrition therapy: the development and initial validation of a novel risk assessment tool. Crit Care 2011, 15:R268.

22. Ginwalla M, Biblo LA, Paydak H: Torsade de pointes following intravenous haloperidol administration in a patient with complete heart block. WMJ 2009, 108:48-50

23. O'Brien JM, Rockwood RP, Suh Kl: Haloperidol-induced torsade de pointes. Ann Pharmacother 1999, 33:1046-1050.

24. Perrault $L P$, Denault AY, Carrier M, Cartier R, Belisle $S$ : Torsades de Pointes secondary to intravenous haloperidol after coronary bypass grafting surgery. Can J Anaesth 2000, 47:251-254.

25. Sharma ND, Rosman HS, Padhi ID, Tisdale JE: Torsades de Pointes associated with intravenous haloperidol in critically ill patients. Am J Cardiol 1998, 81:238-240.

26. Moher D, Schulz KF, Altman DG: Consort: the CONSORT statement: revised recommendations for improving the quality of reports of parallel group randomized trials. BMC Med Res Methodol 2001, 1:2.

27. Ely EW, Inouye SK, Bernard GR, Gordon S, Francis J, May L, Truman B, Speroff T, Gautam S, Margolin R, Hart RP, Dittus R: Delirium in mechanically ventilated patients: validity and reliability of the confusion assessment method for the intensive care unit (CAM-ICU). JAMA 2001, 286:2703-2710.

28. Ely EW, Margolin R, Francis J, May L, Truman B, Dittus R, Speroff T, Gautam S, Bernard GR, Inouye SK: Evaluation of delirium in critically ill patients: validation of the confusion assessment method for the intensive care unit (CAM-ICU). Crit Care Med 2001, 29:1370-1379.

29. Vreeswijk R, Toornvliet A, Honing MLH, Bakker K, de Man T, Daas G, Spronk P, de Jonghe JF, Kalisvaart KJ: Validation of the Dutch version of the confusion assessment method (CAM-ICU) for delirium screening in the intensive care unit. Netherlands Journal of Critical Care 2009, 13:73-78.

30. Schuurmans MJ, Shortridge-Baggett LM, Duursma SA: The delirium observation screening scale: a screening instrument for delirium. Res Theory Nurs Pract 2003, 17:31-50.

31. Abdo WF, van de Warrenburg BP, Burn DJ, Quinn NP, Bloem BR: The clinical approach to movement disorders. Nat Rev Neurol 2010, 6:29-37.

32. Barr J, Fraser GL, Puntillo K, Ely EW, Gelinas C, Dasta JF, Davidson JE, Devlin $J W$, Kress JP, Joffe AM, Coursin DB, Herr DL, Tung A, Robinson BR, Fontaine DK, Ramsay MA, Riker RR, Sessler CN, Pun B, Skrobik Y, Jaeschke R, American College of Critical Care Medicine: Clinical practice guidelines for the management of pain, agitation, and delirium in adult patients in the intensive care unit. Crit Care Med 2013, 41:263-306.

33. Schweickert WD, Pohlman MC, Pohlman AS, Nigos C, Pawlik AJ, Esbrook CL, Spears L, Miller M, Franczyk M, Deprizio D, Schmidt GA, Bowman A, Barr R, McCallister KE, Hall JB, Kress JP: Early physical and occupational therapy in mechanically ventilated, critically ill patients: a randomised controlled trial. Lancet 2009, 373:1874-1882.

34. Kompas F: Farmacotherapeutisch Kompas 2012. Amstelveen: Prelum Uitgevers; 2012.

35. Gandek B, Ware JE, Aaronson NK, Apolone G, Bjorner JB, Brazier JE, Bullinger M, Kaasa S, Leplege A, Prieto L, Sullivan M: Cross-validation of item selection and scoring for the SF-12 health survey in nine countries: results from the IQOLA project. International Quality of Life Assessment. J Clin Epidemiol 1998, 51:1171-1178.

36. O'Brien PC, Fleming TR: A multiple testing procedure for clinical trials. Biometrics 1979, 35:549-556.

37. Heymann A, Radtke F, Schiemann A, Lutz A, MacGuill M, Wernecke KD, Spies C: Delayed treatment of delirium increases mortality rate in intensive care unit patients. J Int Med Res 2010, 38:1584-1595.

doi:10.1186/1745-6215-14-400

Cite this article as: van den Boogaard et al:: Prevention of ICU delirium and delirium-related outcome with haloperidol: a study protocol for a multicenter randomized controlled trial. Trials 2013 14:400.

\section{Submit your next manuscript to BioMed Central and take full advantage of:}

- Convenient online submission

- Thorough peer review

- No space constraints or color figure charges

- Immediate publication on acceptance

- Inclusion in PubMed, CAS, Scopus and Google Scholar

- Research which is freely available for redistribution

Submit your manuscript at www.biomedcentral.com/submit
C Biomed Central 